\title{
Fatigue failure of cancellous bone: a possible cause of implant migration and loosening*
}

The incidence of aseptic loosening can be predicted from migration measurements for proximal femoral, ${ }^{1-4}$ proximal tibial $^{5,6}$ and acetabular components. ${ }^{7}$ A common pattern of migration has an initial rapid phase while the implant is settling into a layer of necrotic bone. ${ }^{8}$ This is followed by a slower continuous phase, the rate of which has been linked to later failure, but the cause of this is uncertain. The rate of medium-term migration depends on the method of fixation; press-fit prostheses migrate significantly more than cemented and osseo-integrated devices. The nature of both phases of migration suggests that it is a mechanical phenomenon, or at least mechanically triggered, rather than a biological process.

Current theories of aseptic loosening cannot account for this pattern of migration. In cemented replacements, the debonding of either of the cement interfaces may initiate aseptic loosening, ${ }^{9}$ but this theory assumes that loosening begins some years after surgery. Migration measurements indicate that loosening often begins very soon after implantation. $^{6}$

Bone resorption, perhaps due to stress shielding, has been suggested as the primary mode of failure of cementless femoral prostheses. ${ }^{10}$ Stress shielding, however, affects mainly the cortex and not the bone immediately around the prosthesis. The fibrous encapsulation of press-fit prostheses produced by micromotion ${ }^{11}$ will allow migration, but this is not applicable to well-cemented and osseo-integrated prostheses. Osteolysis related to wear fragments contributes to late loosening, but this is unlikely to be a factor in early failure. Medium-term migration therefore appears to be due to the compaction or resorption of periprosthetic bone. ${ }^{12}$ All prostheses are supported by cancellous bone, and we consider that medium-term migration may be due to the failure of cancellous bone caused by excess stress.

Our finite-element studies have shown increased stress in the cancellous bone around implanted femoral stems, ${ }^{13,14}$ for several cemented, osseo-integrated and press-fit pros-

* Based on the winning essay for the Gisela Sturm Award of EFORT for Innovation in Artificial Joint Replacement. Full manuscripts of the essay are available from Mr Taylor.

M. Taylor, B Eng, MSc, Research Assistant

K. E. Tanner, MA, DPhil, Reader

IRC in Biomedical Materials, Queen Mary and Westfield College, Mile End Road, London E1 4NS, UK.

(C)1997 British Editorial Society of Bone and Joint Surgery 0301-620X/97/27461 \$2.00

J Bone Joint Surg [Br] 1997;79-B:181-2. theses for which migration and survivorship data are available. ${ }^{1,15,16}$ Cemented and osseo-integrated prostheses were shown to generate twice the stress in cancellous bone than that in the normal intact femur, rising to over three times in press-fit stems. These theoretical stresses in cancellous bone all exceeded the in vitro fatigue strength of such bone, which confirms the possibility of collapse of cancellous bone over extended periods of time. There was a positive correlation between our predicted cancellous bone stresses and the migration measured in clinical cases at two years postoperatively. We have found a similar relationship between the initial stress in cancellous bone and migration for proximal tibial prostheses (Taylor et al, unpublished work).

It is well known that trabecular microfractures, healing by callus, are present in the cancellous bone of healthy ${ }^{19}$ and osteoarthritic ${ }^{18}$ femoral heads, but in the normal condition such damage seems to be in equilibrium with the remodelling response. Increased stress will disturb this equilibrium by increasing the rate of damage.

Any implant is initially supported on a necrotic layer of cancellous bone with mechanical properties similar to living bone, but no ability to repair. At first there will be accelerated failure of this dead cancellous bone. Even after the necrotic layer has been replaced, however, the rate of migration will vary with the ability of vascularised cancellous bone to repair damage. If damage exceeds repair, then it is likely that migration will continue, although at a slower rate than during the initial phase. It will cease if repair equals or exceeds the rate of tissue damage. It has been shown that continuous slow migration may continue for a number of years after implantation of a femoral stem. This suggests that damage accumulation always exceeds repair. Press-fit femoral prostheses are known to migrate significantly more than cemented implants and we have demonstrated by finite-element analysis that they generate higher stress in cancellous bone. This hypothesis is supported by a retrieval study reported by Hahn and Vogel (personal communication) which showed a greater incidence of trabecular fractures and microcalli around press-fit prostheses than around cemented prostheses.

We suggest that the risk of cancellous bone failure, and therefore of migration, is proportional to the magnitude of the stresses in cancellous bone and inversely proportional to its ability to withstand these stresses. The stresses in cancellous bone are governed by the design of the prosthesis and its method of fixation in relation to the weight 
and level of activity of the patient. It may be possible to relate the variation in migration rate between different designs to the changes in the magnitude of the stresses which they generate.

The differences in migration rates found in patients with identical prostheses may be due to differences in the quality of cancellous bone: weak, necrotic tissue fails more often than strong, vital tissue.

The fatigue failure of cancellous bone provides a possible unifying factor for the study of implant migration, regardless of site or method of fixation. It may help to explain the observed patterns of migration and may prove to be a useful adjunct in the design of new prostheses.

M. TAYLOR

K. E. TANNER

\section{REFERENCES}

1. Freeman MAR, Plante-Bordeneuve P. Early migration and late aseptic failure of proximal femoral prostheses. J Bone Joint Surg [Br] 1994;76-B:432-8.

2. Kärrholm J, Malchau H, Snorrason F, Herberts P. Micromotion of femoral stems in total hip arthroplasty: a randomized study of cemented, hydroxyapatite-coated and porous-coated stems with roentgen stereophotogrammetric analysis. J Bone Joint Surg [Am] 1994;76-A: 1692-705.

3. Kärrholm J, Borssén B, Löwenhielm G, Snorrason F. Does early micromotions of femoral stem prostheses matter? 4-7-year stereoradiographic follow-up of 84 cemented hip prostheses. J Bone Joint Surg [Br] 1994;76-B:912-7.

4. Walker PS, Mai SF, Cobb AG, Bentley G, Hua J. Prediction of clinical outcome of THR from migration measurements on standard radiographs: a study of cemented Charnley and Stanmore femoral stems. J Bone Joint Surg [Br] 1995;77-B:705-14.

5. Grewal R, Rimmer MG, Freeman MAR. Early migration of prostheses related to long-term survivorship: comparison of tibial components in knee replacement. J Bone Joint Surg [Br] 1992;74-B: $239-42$
6. Ryd L, Albrektsson BEJ, Carlsson L, et al. Roentgen stereophotogrammetric analysis as a predictor of mechanical loosening of knee prostheses. J Bone Joint Surg [Br] 1995;77-B:377-83.

7. Stocks GW, Freeman MAR, Evans SJW. Acetabular cup migration: prediction of aseptic loosening. J Bone Joint Surg [Br] 1995;77-B: 853-61.

8. Mjöberg B, Selvik G, Hansson LI, Rosenqvist R, Önnerfält R. Mechanical loosening of total hip prostheses: a radiographic and roentgen stereophotogrammetric study. J Bone Joint Surg [Br] 1986; 68-B:770-4.

9. Jasty M, Maloney WJ, Bragdon CR, O'Conner D, Haire T, Harris WH. The initiation of failure in cemented femoral components of hip arthroplasties. J Bone Joint Surg [Br] 1991;73-B:551-8.

10. Huiskes R. Failed innovation in total hip replacement: diagnosis and proposals for a cure. Acta Orthop Scand 1993;64:699-716.

11. Pilliar RM, Lee JM, Maniatopoulos C. Observations on the effect of movement on ingrowth into porous-surfaced implants. Clin Orthop 1986;208:108-13.

12. Linder L. Implant stability, histology, RSA and wear: more critical questions are needed: a view point. Acta Orthop Scand 1994; 65:654-8.

13. Taylor M, Tanner KE, Freeman MAR, Yettram AL, Cancellous bone stresses surrounding the femoral component of a hip prosthesis: an elastic-plastic finite element analysis. Med Eng Phys 1995; 17:544-50.

14. Taylor M, Tanner KE, Freeman MAR, Yettram AL. Finite element remodelling - predictor of implant survival? J Mat Sci Mat Med 1995;6:808-12.

15. Braud P, Freeman MAR. The effect of retention of the femoral neck and of cement upon the stability of a proximal femoral prosthesis. J Arthroplasty 1990;5:s5-10.

16. Kroon P-O, Freeman MAR. Hydroxyapatite coating on hip prostheses: effect on migration into the femur. J Bone Joint Surg [Br] 1992;74-B:518-22.

17. Todd RC, Freeman MAR, Pirie CJ. Isolated trabecular fatigue fractures in the femoral head. J Bone Joint Surg [Br] 1972;54-B: 723-8.

18. Freeman MAR, Todd RC, Pirie CJ. The role of fatigue in the pathogenesis of senile femoral neck fractures. J Bone Joint Surg [Br] 1974;56-B:698-702. 